suddenly recovered his conscionsness, and was able to speak, though very imperfectly : but the other symptoms remained unabated. He gradually sank, and died on the morning of the thirteenth day ; the extraordinary secretion of sweat and urine continuing to the last. There was no dissection. Here, again, the symptoms of disturbance in the nervous centres, and the abnormal excitement of the secreting organs, were coincident.

Torquay, November 27, 1849.

\title{
CASE OF IDIOPATHIC TETANUS SUCCESSFULLY TREATED.
}

By THOMAS BeviLL PEACOCK, M.D., Assistant Physician to St. Thomas's Hospital.

Tнобан cases of Idiopathic Tetanus, and those in which the symptoms supervene gradually, are usually more tractable than the traumatic and acute forms; yet, as the disease is, under all circumstances, so frequently fatal in its result, it is conceived that the following may be worthy the notice of the profession.

Case. Samuel Sessions, a labourer, residing at East Acton, fortyeight years of age, was admitted into the Royal Free Hospital, on the 2nd of November, 1847. He stated, at the time of his admission, that he had taken cold on the 17 th of October, while working in a potatoe field and perspiring, and shortly after felt some stiffiness, and difficulty of moving the left leg; this was followed by similar stiffness of the right leg, and cramp in the back; and subsequently the neck and muscles of the jaws became affected. On the 21st, he was scarcely able to open his mouth; and when he succeeded in separating his jaws, they suddenly snapped to, and bit his tongue. Since this time, he had been quite incapable of taking any solid food. Soon after the locked-jaw came on, he began to suffer occasionally from severe spasms, more especially when he made any exertion, as in the effort of getting out of bed. In these attacks the body was drawn back, the legs extended, and the stomach became hard and painful. He had several paroxysms of this description during the last week; and the day before his admission, he had one more severe than any of the former attacks. He stated, that though formerly of intemperate habits, he had latterly lived regularly, and had been but poorly off for some time.

When seen on the 3rd of November, he expressed a wish to be got out of bed; but, immediately on placing his foot to the floor, he was seized with one of the severe paroxysms. His body became arched backwards, his limbs were rigidly extended, the abdomen was excessively tense, and the muscles of the jaws contracted, and he cried out from the severity of the pain in the epigastrium and back; the pulse also became very hard and rapid. When the attack subsided, the pulse became feeble and less frequent, the face was pale, and there did not appear to be any tenderness of the spine; the jaw could with difficulty be opened to a small extent, and the tongue was found dry and furred; the bowels were confined, and had been so from the com- 
mencement of his illness. He was directed to take a purgative draught. immediately, and afterwards to have two grains of calomel and one of opium three times daily, and to be cupped to $8 \mathrm{oz}$. in the course of the spine; to have port wine and beef-tea at intervals.

November 4 . The medicines prescribed have been given to him, and he has been cupped, and has passed a better night, having slept at intervals. The bowels have been freely acted upon; the pulse is 76 and feeble, the skin cool; the mouth admits of being somewhat more opened, and he can protrude the tongue better,-it is less furred; the body is drawn somewhat back, and the abdomen is excessively tense; he complains of the severe pain which he experiences at intervals in the pit of the stomach. The pain, he says, is increased on pressure. He has not had any of the more severe paroxysms during the night. He was directed to continue to take the calomel and opium with the wine and beef-tea; and, if the spasms should return, to inhale ether.

He had a severe spasmodic attack on the evening of the 4 th, and the ether was therefore administered. He inhaled it for three or four minutes, and then became insensible, and the spasms relaxed, but recurred almost immediately afier he recovered his consciousness. The inhalation was then repeated; and, this time, it was followed hy more decided and permanent relaxation of the cramps and relief from pain. At 12 o'clock at night, however, the state of rigidity had returned, and the cramps were becoming severe; the ether was therefore again inhaled; and though there was entire relaxation after this for a short time, in about twenty minutes he had a more severe spasmodic attack than any which he had previously had since his admission. It was evident, that the ether did not exercise any permanently favourable influence; and he was therefore placed in a blanket wrung out of hot water, and this again was wrapped in two or three other dry blankets; he remained so " packed" from 10 P.M. on the 5th, to 6 A.M. on the 6th.

November 6. To-day there is an evident amendment in his symptoms. He states that he has passed a comfortable night, and has slept at intervals. The permanent contraction still continues, so that his body is arched backwards and the abdomen is tense; but he has been entirely free from the severe spasms, and has less pain in the epigastrium. He can open the mouth a little more, and is able to protrude the tongue better. The pulse is 100 and quiet; the tongue slightly furred. He perspired profusely, but felt quite warm and easy during the night, and says, that the bath has afforded him great relief. The gums are affected by the calomel. The bowels have been freely acted upon, and he makes water freely. He has taken his wine and beeftea well.

To repeat the calomel and opium pills to-night, and afterwards omit them. To take half-an-ounce of port wine, and one drachm of the connpound tincture of bark, every hour, and to have a turpentine enema at night, and use the blanket bath, should the paroxysms recur.

November 8 . On the evening of the 6th, he had a severe attack of spasms, and was immediately put in the hot and damp blanket, and packed as before. The paroxysm soon gave way, and he has had no attack since; but, at his own wish, he was wrapped in the blankets again last night. His body is now much less drawn backwards, the abdomen is less vOL. 1 I. 
tense, and he can open the mouth and protrude the tongue without much difficulty. The pulse is 92 and quiet; the skin cool and moist; the bowels were three times relieved after the enema, and twice yesterdax.

To take the wine and bark every two hours, and use the blanket if necessary.

November 12. He has had no return of the severe spasms, and the permanent cramp of the muscles of the back and abdomen has nearly subsided. He has still some stiffness of the muscles of the jaws and neck, and the face has not altogether lost its rigid appearance; the eyebrows and forehead being still corrugated and contracted. He can now lie in any position; the pulse is of good volume, and quiet; the tongue is clean, and the bowels act naturally. Since the 10th he has taken the bark and wine only every four hours, but, at his own request, he has had the blanket bath for a short time each evening; and, whenever he feels the spasms, he immediatels applies for it.

November 16. He is now gaining strength, and for the last few days has been able to take some solid food. The spasms have not altogether left the muscles of the face and neck, but all remuins of the cramp of the abdominal and spinal muscles have entirely disappeared. The blanket bath has been occasionally used. From this time he did not again have recourse to it; and he was discharged, cured, on the 24 th.

Remarks. In reference to this case, I have few comments to offer. The features which the disease presented, are sufficiently characteristic of Tetanus; and the course of treatment pursued requires little explanation. Few practitioners will probably be now found to contest the conclusion of Mr. Curling, that Tetanus is a functional affection, and not necessarily connected with inflammation of any portion of the nervous system. Yet there can be little doubt, that the disease is occasionally dependent on, or cannected with, excited action of the spinal cord or its membranes; and this would appear to be especially the case when it arises after exposure to cold, etc. Taking this view of the pathology of the disease, I thought it well to commence the treatment of the case with mild antiphlogistic measures; a small quantity of blood was abstracted, by cupping, from the neighbourhood of the spine; the bowels were relieved by aperients, and calomel and opium were prescribed; and, though the febrile symptoms were at no time very marked, this treatment was obviously productive of benefit. The spasms, however, continued to recur; and, on the third day after his admission, he was directed to inhale ether. This was repeated several times; but, though in each instance temporary relaxation ensued, no permanent relief was obtained, and the spasms became more frequent and severe. On the evening of the fourth day, the packing in the hot and moist blanket was therefore had recourse to ; and the beneficial effect of this application was attested, not only by the obvious relief which followed its first employment, but by the anxiety of the patient to recur to its use, whenever there was the slightest return of spasm, and to continue it till every symptom of the disease had subsided. Throughout the course of the attack, the patient's strength was supported by the free exhibition of animal form in a liquid form, with stimulants and tonics. 
It is very generally admitted, that in Tetanus, few remedies afford greater relief than the warm bath; but, as ordinarily employed, its use can be continued for only a short time, and the frequent changes which it necessitates, are often injurious to the patient, by exciting the spasms or increasing their severity. To these objections the blanketbath is not exposed. If the wet blanket be not too much wrung out, and the water be very hot, and if the patient be well packed in dry blankets externally, the heat and moisture may be long retained, and he may lie for many hours undisturbed, and during this time, food, stimulants, and other remedies may be administered. The packing may also be made the means of administering anodynes through the medium of the skin.

During the period of nearly four years that I was connected with the Royal Free Hospital, I had uuder my care another case of Idiopathic Tetanus, which occurred in a man, forty-seven years of age, a labourer, who had taken cold while working in the fields. The attack was more acute and severe than that which I have just detailed : he was admitted on the third day of the disease, and died on the sixth. The treatment pursued consisted in the exhibition of antimony, calomel, and opium, with the warm bath. His death was probably accelerated by an attempt to introduce a tube down the csophagus, for the purpose of administering food. While resident in the Royal Infirmary of Edinburgh, I also witnessed a case of Idiopathic Tetunus, which proved fatal. I mention these cases, as Mr. Curling has stated that Idiopathic Tetanus is, in this climate, rarely a fatal disease. On the contrary, however, it will be seen, that of the three cases which have fallen under my personal observation, wne only has terminated favourably.

20, Finsbury Circus, December 1849.

\section{FATAL CASE OF GASTRO-INTESTINAL HAMORRHAGE FROM CARDIAC DISEASE, WHILST UNDER THE INFLUENCE OF MERCURY.} By W. WHITE COOPER, Eaq., F.R.C.S., Senior Surgeon to the North London
Infirmary for Diseases of the Eye.

Mr. V. S., a merchant from Havannah, consulted me on the 31 st October 1848. His statement was, that he had suffered, on several occasions, from severe febrile and liver attacks; and that, for some time previously, he had been annoyed with fits of vomiting of bile, pain in the right shoulder and side, etc. Whilst travelling on the continent, about two months before I saw him, he remarked that the flames of candles, when viewed with the left eye, appeared as blue as a Bengal light; he was teased with frequent musca and scintillations, pain over the brow, and headache; and objects appeared indistinct, as if seen through a film or mist.

On examination of the eye, the pupil was found to be contracted and nearly motionless, and the sclerotic had an unhealthy murky aspect; the largest type was discerned with great difficulty, and he could merely 